\title{
CONVERSION OF DESSERT COOLER INTO LOW COST AIR CONDITIONER USING PELTIER MODULE
}

\author{
Ashwani Sharma ${ }^{1}$, Mayank Kumar ${ }^{2}$, Rajeev Ranjan ${ }^{3}$, A. Adharsh Krishnan ${ }^{4}$ \\ ${ }^{1}$ Assistant Professor, Mechanical and Automation Department, Amity University Lucknow \\ ${ }^{2,3,4}$ Mechanical and Automation Department, Amity University Lucknow
}

\begin{abstract}
This paper describes design and fabrication of dessert cooler with certain modifications so that it can be used as low cost air conditioner. The cooling in conventional cooler is done along Wet Bulb Temperature line that reduces Dry Bulb Temperature but simultaneously it increases specific humidly. This paper aims to reduce this humidity with the use of peltier module. This system provides better results than that of conventional cooler. The only disadvantage observed; is long time required to get the desired cooling effect.
\end{abstract}

Keywords: Dessert Cooler, Peltier Module, Dry Bulb Temperature, Wet bulb Temperature $* * *$

\section{INTRODUCTION}

A dessert cooler is a device that cools air through the evaporation of water [1]. The temperature of dry air can be dropped significantly through the phase transition of liquid water to water vapour (evaporation), which can cool air using much less energy than refrigeration. The air supplied by the conventional air cooler is generally $80-90 \%$ relative humidity; very humid air reduces the evaporation rate of moisture. High humidity in air causes corrosion. The only two mechanical parts in most basic evaporative coolers are the fan motor and the water pump which requires very low maintenance.

This paper presents a peltier moduledriven dehumidification system to control humidity in traditional cooling system. It is low cost and low power consumption system that can find a wide range of applications in urban as well as rural areas.

\section{BACKGROUND}

The heat transfer not only depends on temperature gradient but also on humidity content in the air. In rainy season or in coastal areas though the temperature of the surrounding is less, but we still feel hot because humidity is more [2]. Higher humidity at a given temperature leads to difficulty in heat transfer. For a water droplet to evaporate it absorbs energy that is Latent heat, the amount of heat that is needed to evaporate the liquid, is drawn from its surroundings thus cooling the surroundings. A phenomenon that happens in porous earthen pots that leads to the water inside to be cooler.

Desert coolers are based on the simple principle that when unsaturated air comes in contact with water, the water evaporates. In the process, the moisture content of air increases, while its temperature decreases [1,2]. The resulting cold but moist air is used for providing cooling. Keeping the above in mind, desert coolers employ the processes of cooling adding to humidification (increase humidity). This increasing humidity makes us uncomfortable and its needs to be reduced.

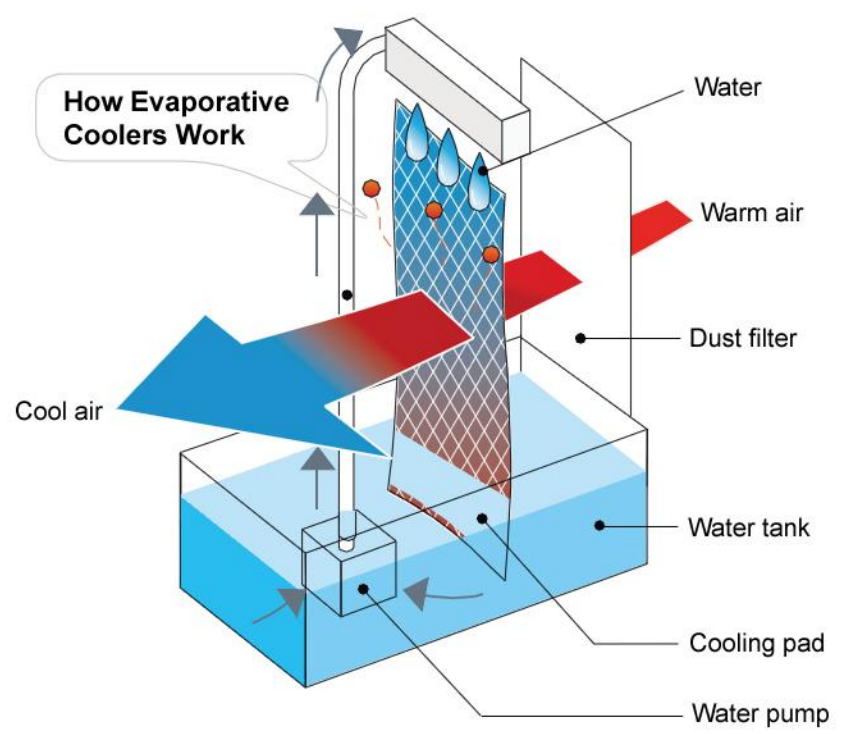

Figure 1: Evaporative Cooler

The thermoelectric effect is the direct conversion of temperature differences to electric voltage and vice versa [3]. The device working on this principle known as Peltier module. The "hot" side is attached to a heat sink so that it remains at ambient temperature, while the cool side goes below room temperature [4]. 


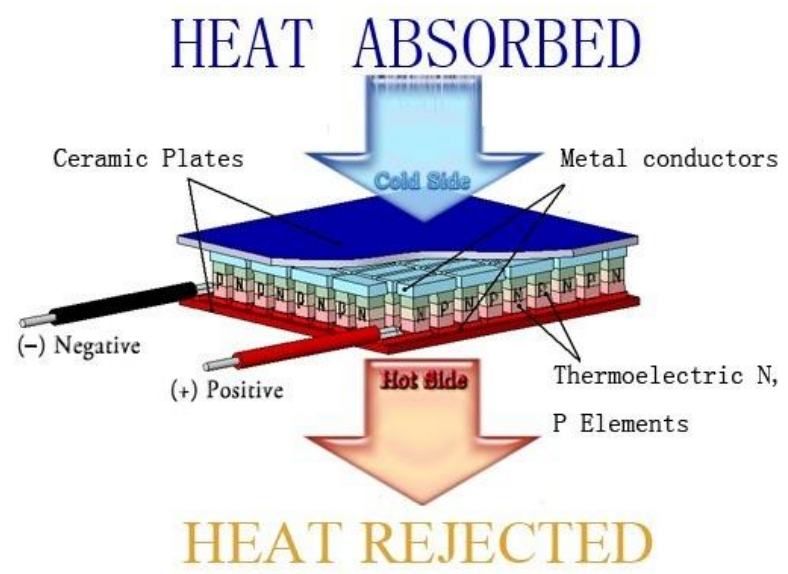

Fig 2: Working of Peltier module

These modules can be used for refrigeration purposes. The time required to get the desired cooling effect is long. In "Portable Peltier Air Conditioner" Peltier plates are used as a cooling unit in combination with conventional desert cooler. This provides better results than conventional desert cooler in terms of air temperature and relative humidity.

\section{SYSTEM DESCRIPTION}

In this system a central cooling unit which consists of Peltier module attached to an aluminum water block. The aluminum water block is filled withbrine solution (refrigerant). The peltier cooling unit is used to cool this brine solution, which is further pumped to the aluminum coil (Heat Exchanger) attached to the conventional air cooler. This coil is placed in front side of the fan of air cooler. When the brine solution is made to flow through the coil its condense the moisture and also decreases the temperature of the air coming out of the cooler to a considerable limit and cooling and partial dehumidification is obtained.

All the arrangement is done according to the block diagram shown. When the cooler start working pump present in sump pumps water to the cooling pad from there a distributer sends some water to the cooling unit with the help of connecting pipes by the help of gravity. In cooling unit Peltier plate and cooler fan are arranged with cooling block as shown in block diagram. Water at the cooling unit is further cooled. The small aquarium pump present in cooling unit pumps this water to heat exchanger tube with help of connecting tubes which is placed if front of the cooler fan which further cools air coming out of cooler and reduces its moisture also. Water after circulating through the heat exchanger tube flows to the sump of the dessert cooler which makes complete cycle. This process is continued as a result of which the temperature of the room goes decreasing.
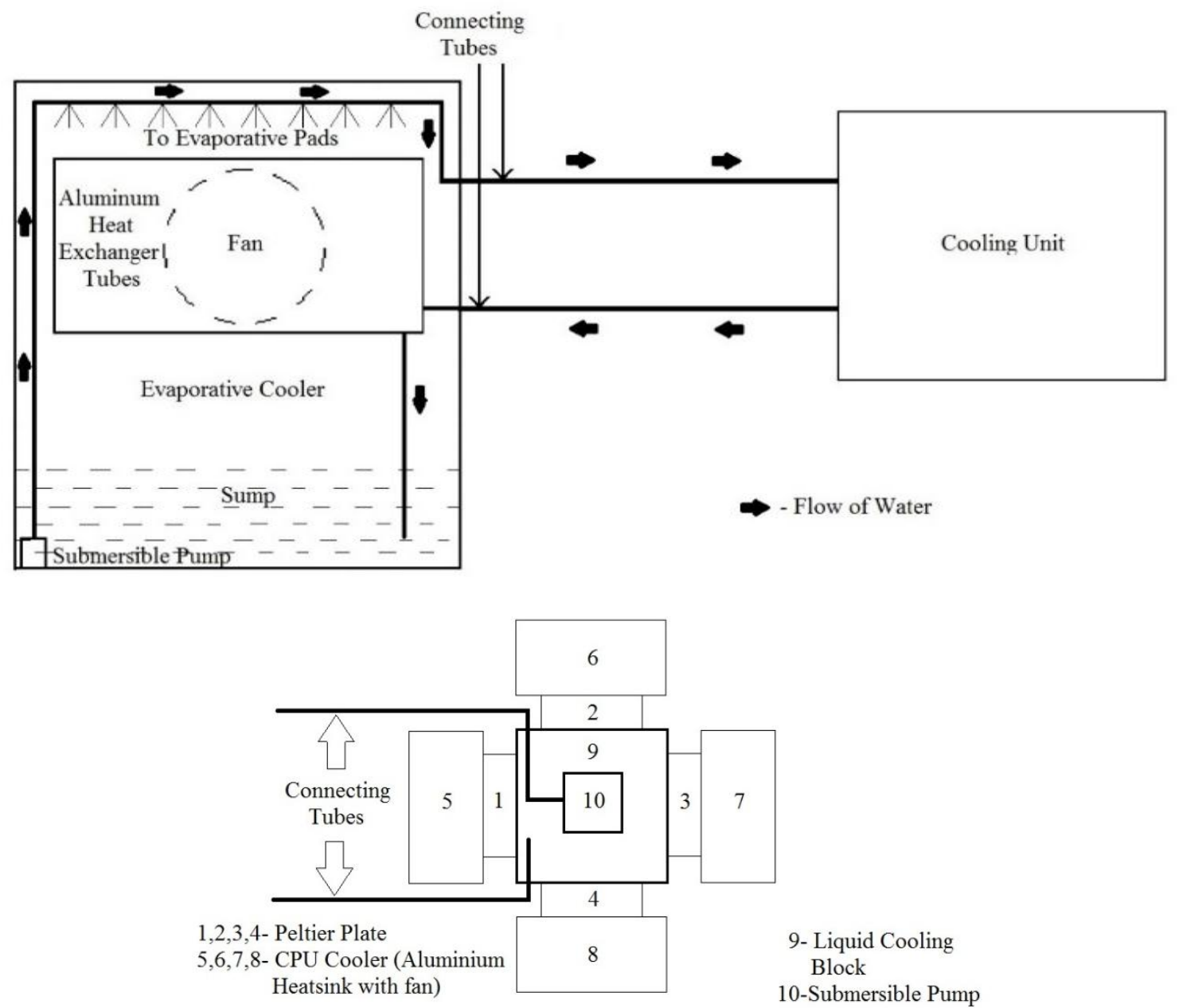

Figure 3: Layout of Peltier Powered Air Conditioner 
This system offers following advantages

A Thermoelectric module works without any moving parts so they are almost maintenance free ${ }^{[5]}$.

* The thermoelectric cooling system is much smaller and lighter [6].

* A Thermoelectric module attached to the heat sink has the ability to reduce the temperature below the ambient value[6].

* Thermoelectric module can heat or cool depending upon the polarity of the applied power. This quality eliminates the necessity of providing separate heating and cooling functions within the same system

* Dehumidification and humidification unit

* Highly efficient during dry as well as humid weather.

\section{This system offers following disadvantages}

* Peltier modules are usually small and are not generally used for large scale refrigeration [7].

* Peltier Coolers also require supply of electricity to work efficiently

* Expensive in the long run.

* Requires a bit of time to cool water in cooling box.

\section{FABRICATION}

The primary components of the refrigeration system are:

\section{a) Peltier Plate}

The thermoelectric plates that can be used here are TEC12706, TEC-12709, TEC-12712, TEC-12715 and TEC$12730^{[7]}$. These are the most reliable and widely used plates in today's market. It is generally powered up by a $12 \mathrm{~V} \mathrm{DC}$ supply. A Switch Mode Power Supply (SMPS) is best suited to power up the plate. The CPU Cooler is pasted to the hot side of the plate by means of thermal paste.

\section{b) Evaporative Cooler}

Evaporative coolers make use of water's large enthalpy of vaporization. Through the phase translation of water into water vapour during evaporation, the temperature of dry air can be dropped remarkably [5]. Evaporative coolers can cool air using much less energy than refrigeration systems. Evaporative coolers are best suitable for use in extreme dry climates.

\section{c) Heat Exchanger}

The heat exchanger tubes used in this system should be made of Aluminum andshould also have heat exchanger fins fixed throughout its surface. This ensures greater efficiency during heat transfer between the tubes and the air that passes through it. A typical Aluminum heat exchanger is shown below.

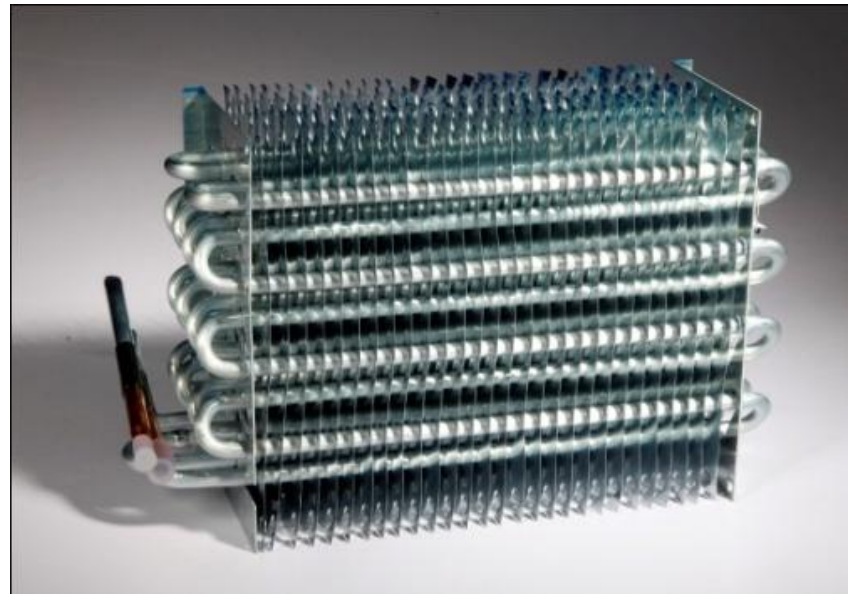

Fig.4 Heat Exchanger

\section{d) Heat Sink}

Heatsink made of Aluminum is pasted to the hot junction of the thermoelectric plate by means of thermal paste. The thermal paste is used specifically in order to prevent any losses in the heat transfer between the thermoelectric plate and the heatsink. The radiator fan is used to take away the heat from the fins of the Aluminum heatsink. The arrangement of the Aluminumheatsinks and the radiator fan is shown below.

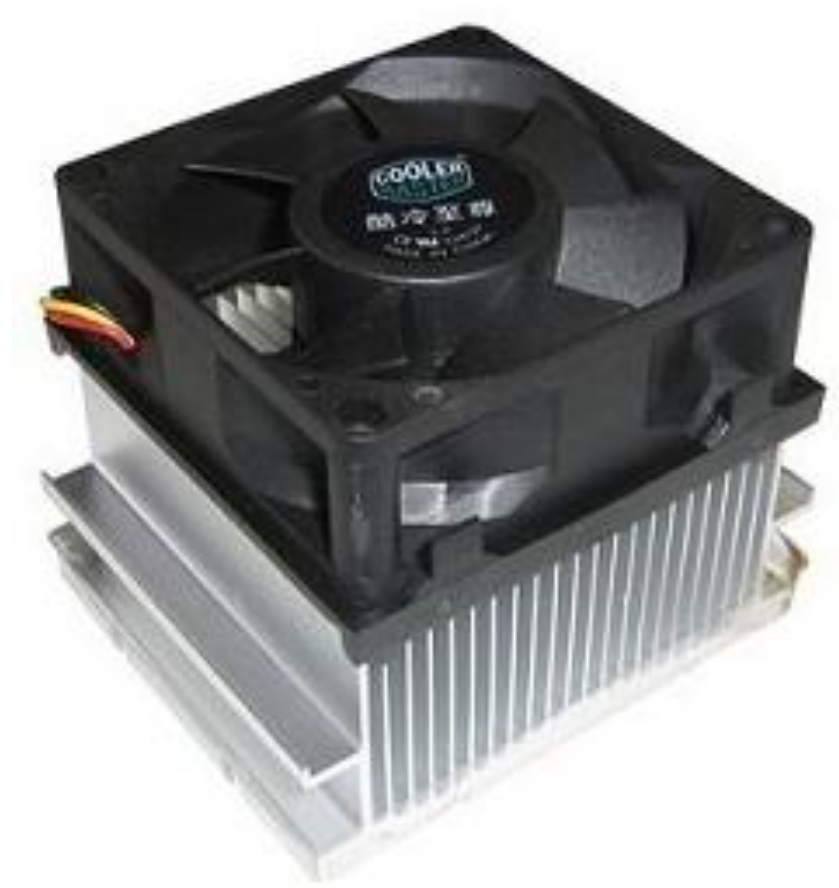

Fig 5: Heat Sink

\section{e) Liquid Cooling Block}

A liquid cooling block with the same surface area as that of the thermoelectric plate is attached to the cold junction of the plate by means of thermal paste. The following images describe the block clearly. The sides of the block that are not in contact with the Peltier plates are generally insulated. 


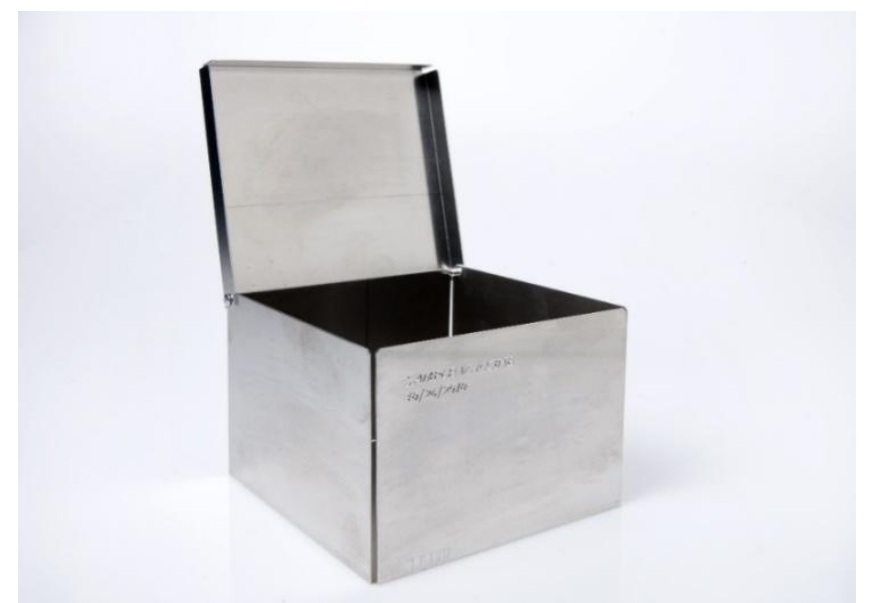

Fig.6 Cooling Block

\section{f) Submersible Pump}

A submersible pump is placed inside the liquid cooling block. It pumps the water from the liquid cooling block to the Aluminium heat exchanger tubes. The water then flows into the sump of the evaporative cooler by gravity.

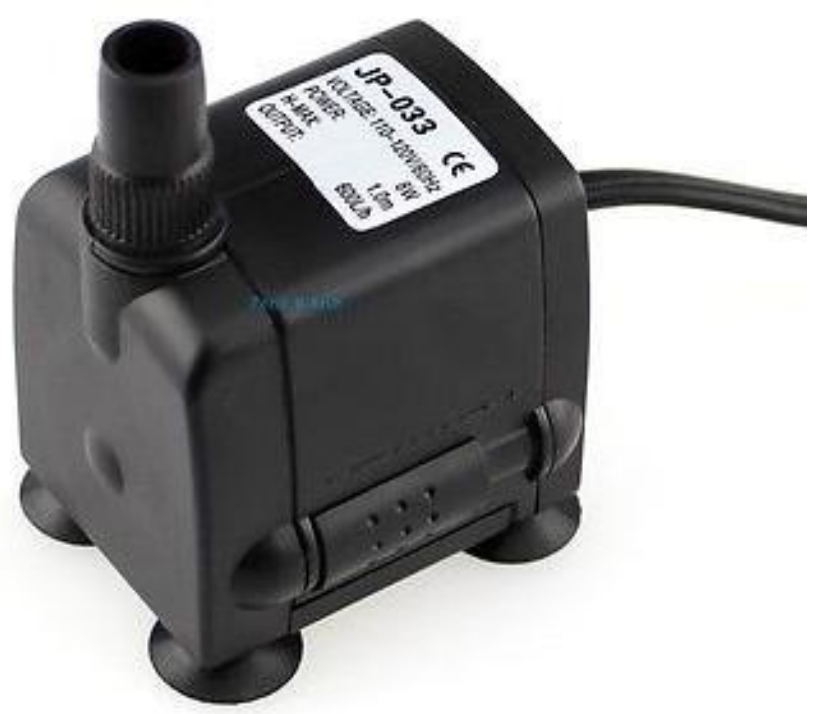

Fig 7: Submersible Pump

\section{PERFORMANCE ANALYSIS}

The output of Peltier Plate Air Conditioner is:

1. Lower room temperature is achieved.

2. Humidity of cooled air coming out of Peltier plate air conditioner is less than conventional dessert cooler.

These results are verified by comparing the results of

a) Room temperature using Peltier Plate air conditioner and conventional dessert cooler.

b) Humidity of air coming out of air conditioner and conventional desert cooler.

Reading is taken for 6 hours in two says Day 1: On Peltier plate air conditioner. Day 2: On conventional dessert cooler.
Readings: WBT and DBT is obtained from experimental readings and $\mathrm{RH}$ is calculated by using website [8] given in the reference.

\section{Initial Condition:}

Ambient temperature: $42^{\circ} \mathrm{C}$

Relative humidity: $16 \%$

Table 1: Comparison between temperature of room using Peltier plate air conditioner \& conventional dessert cooler.

\begin{tabular}{|l|l|l|l|}
\hline $\begin{array}{l}\text { Sr. } \\
\text { No. }\end{array}$ & $\begin{array}{l}\text { Time } \\
\text { (min) }\end{array}$ & $\begin{array}{l}\text { Conventional } \\
\text { dessert cooler } \\
\text { (room temp. in } \\
{ }^{\circ} \text { C) }\end{array}$ & $\begin{array}{l}\text { Peltier Plate } \\
\text { AC (room } \\
\text { temp. in }{ }^{\circ} \text { C) }\end{array}$ \\
\hline 1. & 30 & 36 & 36 \\
\hline 2. & 60 & 34 & 34 \\
\hline 3. & 90 & 33 & 33 \\
\hline 4. & 120 & 31.5 & 32 \\
\hline 5. & 150 & 30 & 31 \\
\hline 6. & 180 & 28.5 & 30 \\
\hline 7. & 210 & 29 & 28 \\
\hline 8. & 240 & 28 & 27 \\
\hline 9. & 270 & 28 & 26 \\
\hline 10. & 300 & 27 & 24.5 \\
\hline 11. & 330 & 27 & 24 \\
\hline 12. & 360 & 27 & \\
\hline & & & 24 \\
\hline
\end{tabular}

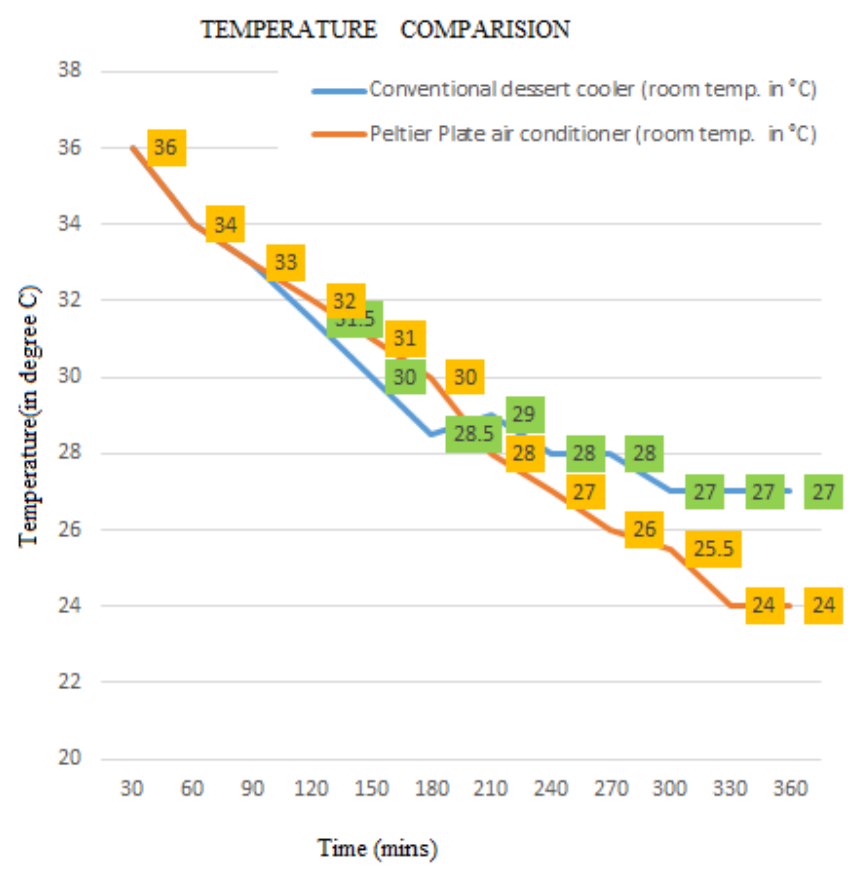

Fig 8: Temperature (Cooler V/s Peltier AC) 
From the reading of table 1 it was observed that after $6 \mathrm{hrs}$ the room temperature decreases from $42^{\circ} \mathrm{C}$ to $24^{\circ} \mathrm{C}$ by using Peltier Plate AC. The room temperature with help of conventional dessert cooler is $27^{\circ} \mathrm{C}$ and with Peltier Plate is $24^{\circ} \mathrm{C}$ which is $3^{\circ} \mathrm{C}$ less than conventional dessert cooler.

Table 2: Comparison between RH of room using Peltier plate air conditioner \& conventional dessert cooler.

\begin{tabular}{|l|l|l|l|}
\hline $\begin{array}{l}\text { Sr. } \\
\text { No. }\end{array}$ & $\begin{array}{l}\text { Time } \\
(\mathbf{m i n})\end{array}$ & $\begin{array}{l}\text { Conventional dessert } \\
\text { cooler (RH \%) }\end{array}$ & $\begin{array}{l}\text { Peltier Plate } \\
\text { AC } \\
(\text { RH \%) }\end{array}$ \\
\hline 1. & 30 & 36 & 36 \\
\hline 2. & 60 & 38.3 & 38.3 \\
\hline 3. & 90 & 39.9 & 39.9 \\
\hline 4. & 120 & 47.2 & 42.2 \\
\hline 5. & 150 & 50 & 49.4 \\
\hline 6. & 180 & 58.8 & 53.6 \\
\hline 7. & 210 & 62.7 & 56.1 \\
\hline 8. & 240 & 67.9 & 58 \\
\hline 9. & 270 & 70.3 & 60 \\
\hline 10. & 300 & 74 & 64 \\
\hline 11. & 330 & 76.3 & 64.5 \\
\hline 12. & 360 & 79.8 & 65.8 \\
\hline & & & \\
\hline
\end{tabular}

\section{HUMIDITY COMPARISION}

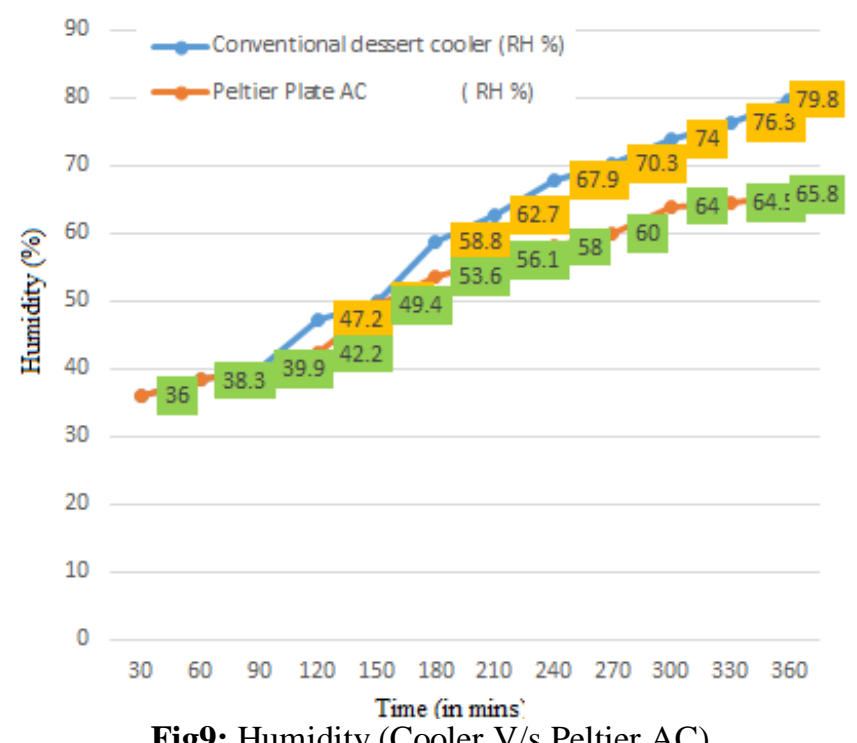

Fig9: Humidity (Cooler V/s Peltier AC)

From the reading of table 2 we observed that in $6 \mathrm{hrs}$ the relative humidity of room is increased from $16 \%$ to $65.8 \%$ by using Peltier Plate air conditioner. The relative humidity with conventional dessert cooler is $79.8 \%$ and with Peltier Plate is $65.8 \%$ which is $14 \%$ less than conventional dessert cooler.

On psychrometric chart the effect of this system on temperature and humidity can be observed

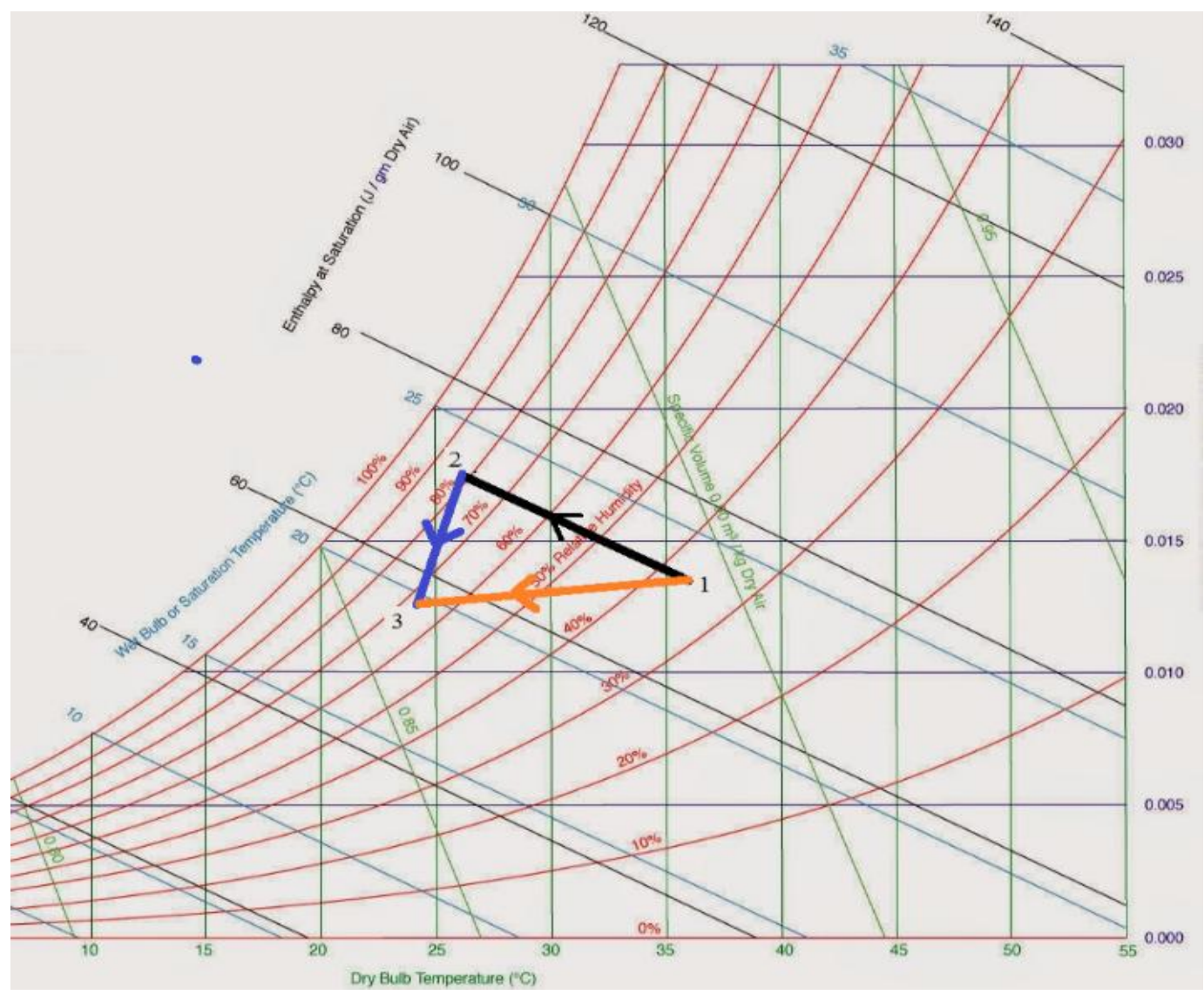

Fig10: Psychrometric Chart 
The Process 1-2 shown by black line represents cooling and humidification process in cooler and the process 2-3 shown by blue line represents cooling by peltier module. So the process 1-3 shown by orange line represents cooling and dehumidification process by the combination of cooler and peltier module.

\section{CONCLUSION}

The cost of the normal air conditioner is around Rs. 28,000 but cost of making Peltier plate air conditioner is quite low. The effectiveness of Peltier plate air conditioner is much better than conventional dessert cooler in terms of humidity and temperature which is proved with this experiment. With further improvement in design the performance of Peltier plate air conditioner can be improved.

\section{REFERENCES}

[1]. O. Amer, R. Boukhanouf, H.G. Ibrahin, "A Review of Evaporative Cooling Technologies", International Journal of Environmental Science and Development, Vol. 6, No. 2, February 2015, pages. 111-117

[2]. Rajesh Maurya, Dr. Nitin Shrivastava, Vipin Shrivastava, "Performance and Analysis of an Evaporative Cooling System: A Review “, International Journal of Scientific \& Engineering Research, Volume 5, Issue 10, October-2014

[3]. Manoj Kumar Rawat, Himadri Chattopadhyay, Subhasis Neogi, "A Review on Developments of Thermoelectric Refrigeration and Air Conditioning Systems: A Novel Potential Green Refrigeration and Air Conditioning Technology", International Journal of Emerging Technology and Advanced EngineeringVolume 3, Feb 2013, pages 362-367

[4]. Benziger B, Anu Nair P\& Balakrishnan P, "Review Paper on Thermoelectric Air-Conditioner Using Peltier Modules" International Journal of Mechanical Engineering Vol. 4, Issue 3, Apr - May 2015, 49-56

[5]. R.S. Khurmi and J.K. Gupta, "Refrigeration and Air Conditioning", S. Chand Publication House, pp 198212(2014)

[6]. https://www.ferrotec.com/Technology/Ther

[7]. moelectric/Thermalref04

[8]. http://www.tech-faq.com/peltier-cooler.html

[9]. http://www.ringbell.co.uk/info/humid.html 